\title{
NOTES ON CASES.
}

By R. Lake.

\section{A SEROUS CYST OF THE AURICLE.}

Serous cysts of the auricle are of sufficient rarity to warrant the following brief notice of one that occurred in my hospital practice. The patient, an intelligent man of about thirty-five, came to my out-patients' department with a tumour of the left ear in the region of the fossa of the antihelix, about $1_{4}^{1}$ by $\frac{3}{4}$ of an inch in diameter.

The history was that four weeks previously there had been noted a small freely movable tumour about the size of a split-pea in the region where the tumour now was; it grew larger gradually at first, but latterly more rapidly. The skin could not be pinched off the cyst wall; it was slightly dusky in hue, not very tense, perfectly translucent, and not very definite at its edges.

A hypodermic needle inserted into the tumour let out a yellow fluid, quite without suspicion of clot and blood in any form.

\section{HERPES OF THE EPIGLOTTIS.}

The following case was sent to me by Dr. Guy Watts, and illustrates the value frequently to be attached to patients' accounts of their ailments : Major X-, an official at the War Office at the time when the authorities suddenly became aware of the task before them in South Africa, was in consequence of the strain induced by long hours, great responsibility, and irregular meals, considerably run down. It happened that the day before any symptoms appeared in the throat, he at one of his meals partook of fresh herring. Late the following night he called in Dr. Watts, and told him that he had swallowed a herring-bone, and that it had stuck in his throat. The most careful examination failed to detect any bone, and early the next morning he came to see if I could find it. I also assumed that his story was correct, and searched in vain for a bone in the usual situations. A laryngeal examination, however, soon put an entirely new aspect on the case; the epiglottis was bright red on its anterior surface, and projecting from this were four small vesicles. A few leading questions settled the matter. The patient had felt the premonitory symptoms, assumed it was a foreign body, recalled the fish, and concluded that the bone had lain perdu for a time, and neglected to mention the fact that he had had no reason for being certain that one was there at all. 